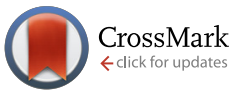

Cite this: Lab Chip, 2017, 17, 76

Received 28th September 2016 Accepted 23rd November 2016

DOI: 10.1039/c6lc01217e

www.rsc.org/loc

\section{On-chip integration of organic synthesis and HPLC/MS analysis for monitoring stereoselective transformations at the micro-scale $\dagger$}

\author{
Josef J. Heiland, ${ }^{a}$ Rico Warias, ${ }^{a}$ Carsten Lotter, ${ }^{a}$ Laura Mauritz, ${ }^{a}$ Patrick J. W. Fuchs, ${ }^{b}$ \\ Stefan Ohla, ${ }^{a}$ Kirsten Zeitler ${ }^{\mathrm{b}}$ and Detlev Belder ${ }^{\star a}$
}

We present a microfluidic system, seamlessly integrating microflow and microbatch synthesis with a HPLC/nano-ESI-MS functionality on a single glass chip. The microfluidic approach allows to efficiently steer and dispense sample streams down to the nanoliter-range for studying reactions in quasi real-time. In a proof-of-concept study, the system was applied to explore aminocatalyzed reactions, including asymmetric iminium-catalyzed Friedel-Crafts alkylations in microflow and micro confined reaction vessels.

Continuous flow chemistry has emerged as a powerful alternative to common batch synthesis to facilitate transformations, which are difficult to conduct with conventional equipment. ${ }^{1-6}$ Microflow technology benefits from superior control over process parameters and even opens up entirely new routes and strategies for chemical synthesis and process optimization. ${ }^{7-18}$ While coil-, tube- or capillary-based reactors are already well established, ${ }^{19-21}$ chipbased devices offer unsurpassed potential for seamless system integration of various functionalities on a single device. ${ }^{22-26}$ Here, especially the combination of chemical transformations and on-the-fly or downstream analytical characterization offers unique insights into chemical processes. ${ }^{27-31}$ The latter can be realized rather simply by applying micro-spectroscopic techniques ${ }^{32}$ such as fluorescence or Raman microscopy or by coupling microfluidic chips to mass spectrometry. ${ }^{33,34}$ However, the selective analytical characterization can be quite challenging in the context of stereoselective conversions. We previously reported on the integration of microflow reactions and chip electrophoresis, which allowed to analyze enantioselective transformations. ${ }^{35-38}$ Chip electrophoresis is techni-

\footnotetext{
${ }^{a}$ Institute of Analytical Chemistry, University of Leipzig, Linnéstr. 3, D-04103 Leipzig, Germany.E-mail: belder@uni-leipzig.de

${ }^{b}$ Institute of Organic Chemistry, University of Leipzig, Johannisallee. 29, D-04103 Leipzig, Germany

$\dagger$ Electronic supplementary information (ESI) available: Experimental details on microchip fabrication and operation, the microfluidic setup and supporting measurements. See DOI: 10.1039/c6lc01217e
}

cally straightforward but has rather limited applications in organic synthesis. ${ }^{39}$ The current state of the art to analyze transformations in continuous micro-flow is using traditional macroscopic HPLC instruments $\mathrm{s}^{40-42}$ as in classical laboratories. Although there is progress in chip-based high-performance liquid chromatography (HPLC), ${ }^{43-48}$ the combination of flow synthesis and high-pressure liquid chromatography on a single device is an unsolved challenge. Since the chipintegration of moving parts, like high-pressure valves, is a major obstacle, the interconnection of a low-pressure continuous flow channel with a HPLC column working at high pressure poses a challenge. This can be overcome if the flows are steered hydraulically with valves and flow restrictors in the outer chip periphery. This concept was applied for on-chip low pressure sample injection ${ }^{48-52}$ and more recently also for the connection of an external flow reactor via transfer capillaries to a 2D HPLC chip. ${ }^{53} \mathrm{~A}$ true integration of micro- or nano-reactors and a HPLC column on the same device is very attractive as it would allow to monitor chemical processes at smallest dimensions in real-time. Such integrated synthesis

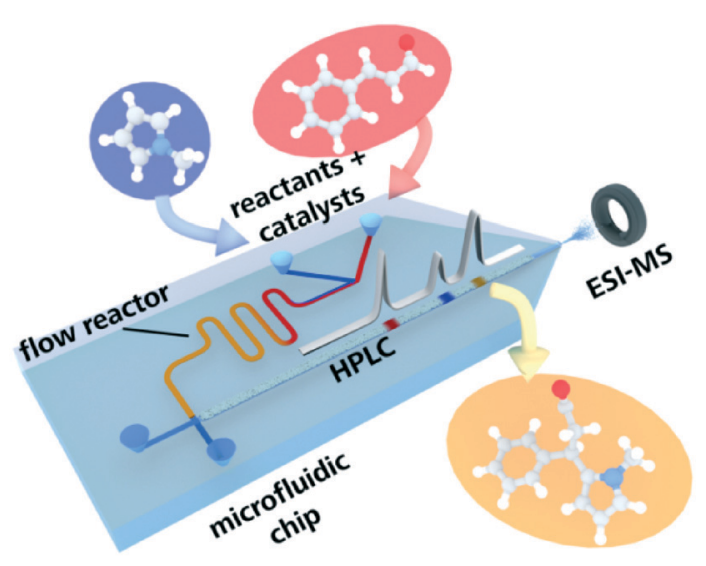

Fig. 1 Schematic representation of the workflow for the direct coupling of microflow synthesis and chiral HPLC-MS analysis on a single microfluidic device. 
and analysis devices are foreseen as enabling technology for future chemical synthesis. ${ }^{54}$

Herein, we present the first example for such a seamless integration of a micro reactor and a packed HPLC column on a single device, which is furthermore hyphenated to mass spectrometry (MS). This is achieved with a tailor-made glass device interconnecting reaction channel and chromatography column in a dead-volume free manner, as schematically shown in Fig. 1. We developed a fluid flow steering method, which enables to dispense nano-liter sized portions of continuous flow as well as micro-batch reactors onto an adjacent HPLC-column.

A photograph of the chip together with microscopic images of key elements such as the transfer cross, the reactor inlet, the sealed column and the electrospray ionization (ESI)-emitter are displayed in Fig. 2. The microchannel layout comprises a $500 \mathrm{nl}$ meandering flow reactor structure connected to a $35 \mathrm{~mm}$ packed-bed chromatographic column via a microfluidic cross junction.

The chromatographic column was generated via common slurry packing through a packing channel, which is sealed thereafter with a photopolymer as described earlier, see Fig. 2(C). This column manufacturing process ${ }^{50}$ allows for the integration of any commercially available HPLC phase material including chiral stationary phases for enantioselective separations. The similarity to common HPLCtechnology greatly facilitates a straightforward method transfer to or from experiments at laboratory scale. At the end of

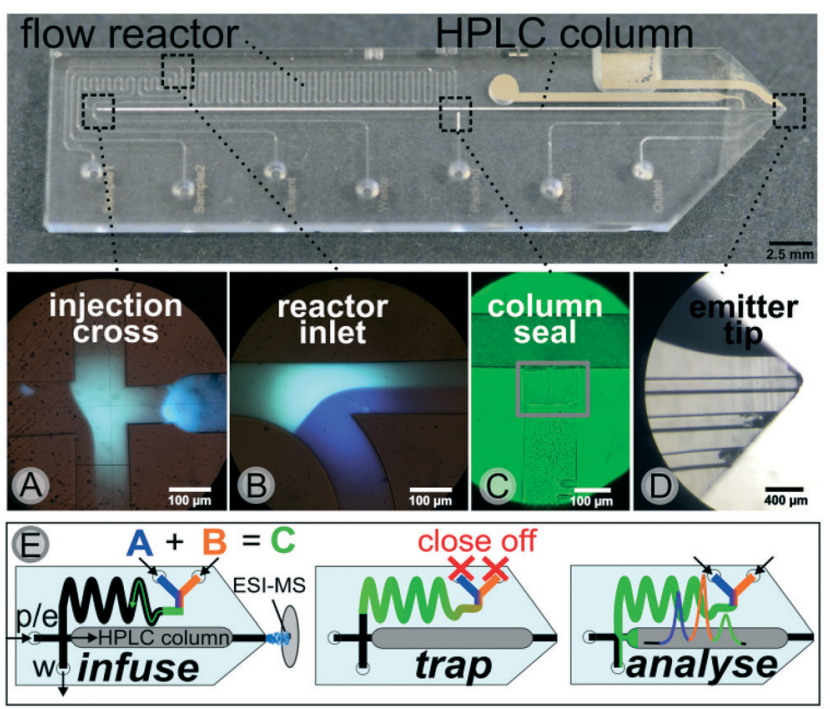

Fig. 2 Photograph of the microfluidic chip with an emitter tip and a packed chromatographic column (top) with all seven fluidic connection ports. Sheath and outlet ports were not used in this work. Micrographs covering four key areas: (A) the injection cross, (B) the reactor inlet, (C) the intersection of packing channel and column compartment and (D) the grinded tip of the microfluidic chip (middle). The bottom row represents a schematic illustration of the underlying working principle for micro-batch analysis with a simplified chip-layout. Besides the two sample inlets (A and B), further fluidic ports are used for pinch and elution flow (p/e) and waste outlet (w). Arrows indicate the direction of flow for each channel. the separation channel a monolithic nanospray emitter for online ESI-MS coupling is implemented. A key functional element of our device is the microfluidic intersection, where the reactor outlet and the column head join, as it enables the crucial sample transfer of the reaction mixture to the HPLCcolumn. For this purpose, the pressure stable glass chip is connected to peripherals such as pumps and valves via home-made steel connection clamps allowing for low dispersion fluidic interfacing at up to 350 bar. ${ }^{55}$ This allows for a controlled steering of the different microflows in an automated way. A detailed technical description of the set-up is provided in the $\mathrm{ESI}^{\dagger} \dagger$ (see Fig. SI-1 and SI-2).

A representative result for the successful on-chip combination of a micro flow reactor and a HPLC separation is shown in Fig. 3. In brief, two reagent streams A and B are merged on-chip and traverse the meandering flow reactor channel. Mixing of the reagents was evaluated with the aid of model dyes and fluorescence microscopy, which proofed mixing within the first $70 \mathrm{nl}$ (see Fig. SI-7†). A portion of the reaction mixture bypassing the injection cross is then transferred by a low pressure sample injection scheme ${ }^{51}$ to the adjacent particulate column. After chromatographic separation of the reaction mixture, detection is performed via nano-ESI-MS.

The chip layout features an optional make-up flow channel, not used in this study, to facilitate mass spec detection with various eluents. ${ }^{52}$

As a first proof-of-concept, the device was applied to study a catalyzed Knoevenagel condensation of an aldehyde and a 1,3-diketone followed by an intramolecular hetero-DielsAlder reaction (Scheme 1). ${ }^{56}$

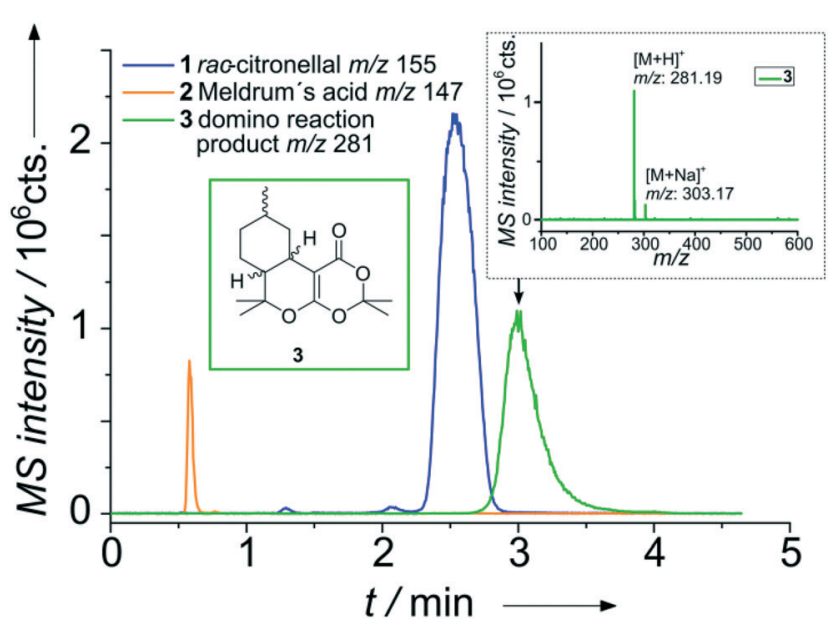

Fig. 3 Extracted ion chromatograms for the separation of the reaction mixture (domino reaction) directly after an on-chip continuous flow synthesis (reaction time $5.4 \mathrm{~s}$, reactor volume approx. $500 \mathrm{nl}$ ). Column: ProntoSIL C18 SH, particle diameter $5 \mu \mathrm{m}$, length $35 \mathrm{~mm}$, mobile phase: $200 \mu \mathrm{l} \mathrm{min}{ }^{-1}, \mathrm{MeOH} / \mathrm{H}_{2} \mathrm{O}(75 / 25 \mathrm{vol} \%$ with $0.1 \%$ formic acid), sample pumps: $10 \mu \mathrm{l} \mathrm{min}{ }^{-1}, \mathrm{MeOH} / \mathrm{H}_{2} \mathrm{O}$ (80/20 vol\%), pinch: $10 \mu \mathrm{l}$ $\mathrm{min}^{-1}, \mathrm{MeOH} / \mathrm{H}_{2} \mathrm{O}$ (50/50 vol\% with $0.1 \%$ formic acid). 12 bar elution pressure at the injection cross at a linear flow rate of $1.10 \mathrm{~mm} \mathrm{~s}^{-1}$ over the column. Reactant inlet A: $1\left(0.1 \mathrm{~mol} \mathrm{l}^{-1}\right)$, reactant inlet $\mathrm{B}: 2(0.12$ $\left.\mathrm{mol} \mathrm{l}{ }^{-1}\right), 5 \mathrm{~mol} \%$ (in relation to 2) EDDA each in $\mathrm{MeOH} / \mathrm{H}_{2} \mathrm{O}(80 / 20$ vol\%). 


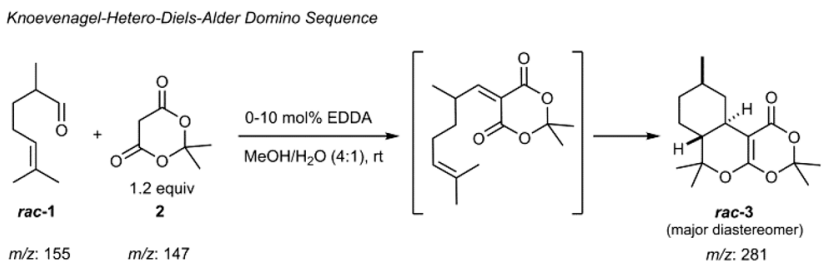

Scheme 1 Model domino reaction: ethylenediamine acetate (EDDA) catalytic Knoevenagel condensation of an aldehyde (rac-citronellal 1) and a 1,3-diketone (Meldrum's acid 2) followed by an intramolecular hetero-Diels-Alder reaction.

For realizing this continuous flow domino reaction, a solution of citronellal $1\left(0.1 \mathrm{~mol} \mathrm{l} \mathrm{l}^{-1}\right.$ in $\left.80 / 20 \mathrm{vol} \% \mathrm{MeOH} / \mathrm{H}_{2} \mathrm{O}\right)$ as well as a mixture of Meldrum's acid $2\left(0.12 \mathrm{~mol} \mathrm{l}^{-1}\right.$ in 80/20 vol\% $\mathrm{MeOH} / \mathrm{H}_{2} \mathrm{O}$ ) with EDDA (10 mol\% with respect to 2 ) as catalyst were introduced in the reactor unit at a flow rate of $10 \mu \mathrm{min}^{-1}$. The flow reactor was then probed with the integrated HPLC column with subsequent MS detection as described above. A representative result for a residence time of 5.4 seconds in the flow reactor is shown in Fig. 3 in terms of a MS chromatogram. Although the sample concentration was rather high, baseline separation of all components was achieved. The excellent chromatographic performance of the column is also evident from the high plate number 3500 (100000 plates $\mathrm{m}^{-1}$ ) for the first eluting peak.

After this initial proof of concept, we further applied the approach to optimize reaction conditions on the microscale. As an example, we studied the effect of the catalyst loading on the reaction by sequential introduction of sample solutions with different EDDA concentrations. As expected, higher catalyst amounts resulted in increased product formation. The results of these set of experiments are summarised in Fig. SI-5, ESI. $\dagger$ Unlike to the more common simple coupling of a flow reactor directly to mass spectrometry the integrated HPLC functionality allows to distinguish between isomeric products with identical mass, ${ }^{57}$ which is evident from Fig. SI-5, $\dagger$ where even diastereomeric products $(\mathrm{m} / \mathrm{z} 281.19)$ are well resolved.

In the above mentioned setup the residence time in the microreactor is determined by the applied sample pump flow rates. At very low flow rates it proved difficult to reliably generate narrow sample plugs on the column head. At such slow reactor flows peak broadening was observed, which can be explained by diffusion or migration of sample components onto the column. Due to the limitations of the current flow steering process based on earlier work, ${ }^{51,52}$ we further developed the approach by effectively separating reactor fluid flow manipulations and the injection process to enable microbatch operation with stopped flow. For this purpose we redesigned and upgraded the outer chip periphery by the addition of pumps, valves and interconnecting tubing. A schematic drawing of the setup and simplified sketches of the working principle are shown in Fig. 4.

By directed valve switching, this set-up enables to trap the reaction mixture inside the integrated $500 \mathrm{nl}$ sized reactor

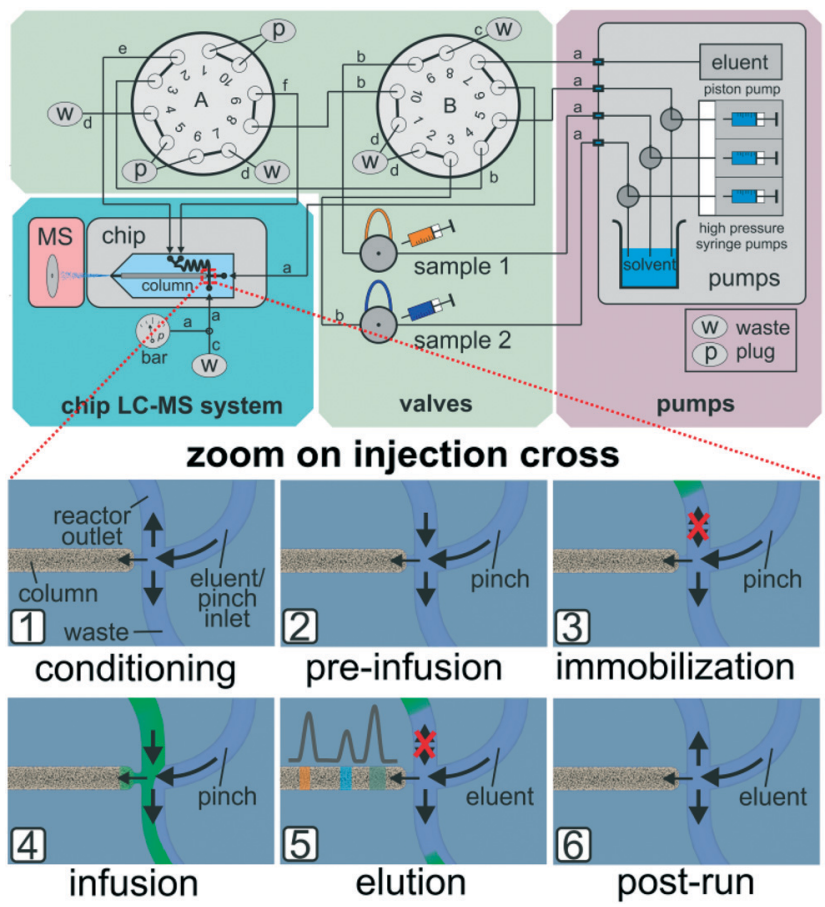

Fig. 4 Schematic overview of the microfluidic setup for stop-flow mode. (top) Further details, like capillary dimensions, are given in the Experimental section. Insets (1) to (6) represent the fluidic situations at the injection cross at all stages of the analytical process. Arrows indicate directions of flow for the individual situations. For multiple injections form a single reactor loading, steps 4 and 5 may be repeated until the reactor volume is depleted (bottom).

channel in a way, that it is not in direct contact with the column head. By switching to injection mode, portions of the reaction mixture can be transferred onto the separation column on demand (see Fig. 4 bottom). In detail, after conditioning the column and reverse flushing the reactor (1), the sample streams are directed to the reactor compartment (2), where they are trapped hydrodynamically by sealing off the inlet ports (3). After the desired reaction time, portions of the reactor effluent can be infused to the column head (4) by pulsed valve switching. The injected amount is eluted over the column while the confined residual reactor content remains unaffected (5). Steps (4) and (5) may be repeated for multiple sequential sampling from the reactor (see Fig. 5). After the experiments, the column and the reactor are put back in conditioning mode (6) and all sample carrying parts are flushed in reverse to prevent cross contamination. Detailed technical information on this enhanced valving procedure is provided in the ESI $\dagger$ (see Fig. SI-8).

This novel set-up now allowed to study much slower reactions and was exemplarily applied to analyze an enantioselective iminium-catalyzed Friedel-Crafts alkylation of methyl pyrrole 4 and cinnamaldehyde 5 with two different chiral imidazolidinone-based catalysts 6 and 8 (see Scheme SI-1†). ${ }^{58-60}$

For this purpose, the two sample streams (inlet A: pyrrole 4, inlet B: aldehyde 5 with catalyst 6 ) were introduced into 


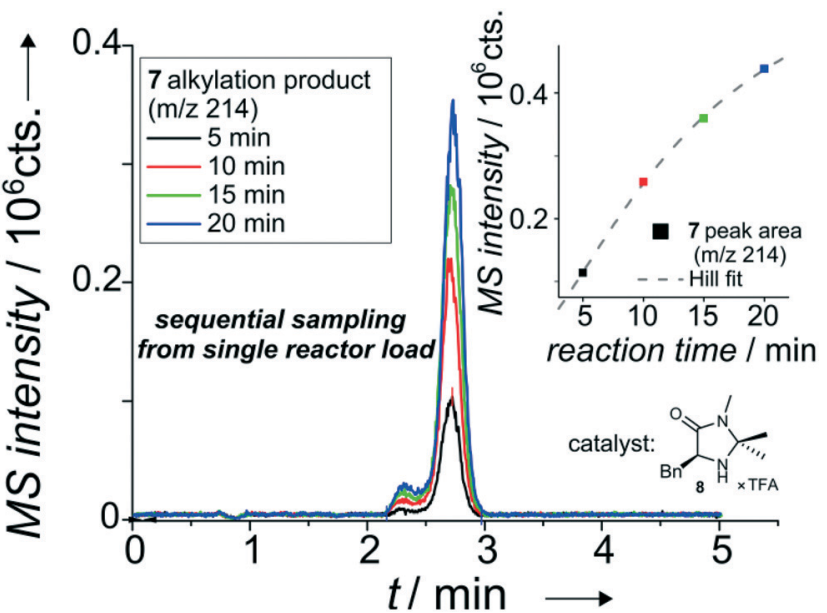

Fig. 5 Overlapped EICs $(\mathrm{m} / \mathrm{z} 214)$ of the alkylation product for sequential sampling of the iminium-catalyzed Friedel-Crafts alkylation see Scheme $\mathrm{SI}-1 \uparrow$ with catalyst 2 (8) from a single reactor load. Based on injection valve switching profile see Table SI-5.† Column: ProntoSIL $\mathrm{C} 18 \mathrm{SH}$, particle diameter $3 \mu \mathrm{m}$, length $35 \mathrm{~mm}$. Mobile phase: $100 \mu \mathrm{l}$ $\mathrm{min}^{-1}, \mathrm{MeOH} / \mathrm{H}_{2} \mathrm{O}(60 / 40$ vol\%) with $0.1 \%$ formic acid. Sample pumps: $10 \mu \mathrm{l} \mathrm{min}{ }^{-1}, \mathrm{MeOH} / \mathrm{H}_{2} \mathrm{O}$ (80/20 vol\%), pinch: $10 \mu \mathrm{lmin}{ }^{-1}, \mathrm{MeOH} / \mathrm{H}_{2} \mathrm{O}$ (50/50 vol\%), reactant inlet A: $4\left(0.1 \mathrm{~mol} \mathrm{l}^{-1}\right)$, reactant inlet $\mathrm{B}: 5(0.05$ $\left.\mathrm{mol} \mathrm{l}{ }^{-1}\right), 20 \mathrm{~mol} \% 6$ or 8 (in relation to 5 ) each in $\mathrm{ACN} / \mathrm{H}_{2} \mathrm{O}(87 / 13$ vol\%). 19 bar elution pressure at the injection cross with immobilized sample plug, at a linear flow rate of $1.09 \mathrm{~mm} \mathrm{~s}^{-1}$ over the column. The isobaric shoulder peak is most probably due to a second, intramolecular Friedel-Crafts alkylation in the acidic environment of the eluent system containing 0.1 vol\% formic acid.

the chip. The combined sample stream was stopped just before it reached the column head and a small portion of the mixture was dispensed on-demand. In the current setup, the $500 \mathrm{nl}$ reactor was filled from two $3.68 \mu \mathrm{l}$ loops, a further reduction in volume is feasible. This dispensing process enables even multiple injections of about $100 \mathrm{nl}$ portions from the $500 \mathrm{nl}$-sized microreactor. The result of a set of four experiments where the $500 \mathrm{nl}$ reactor is consecutively sampled at 5 minute intervals is shown in Fig. 5. As evident from the data, an increase in reaction time results in an improved turnover as expected. This allows detailed kinetic studies of stereoselective reactions performed in micro-confined reactors as displayed in Fig. SI-8 to SI-15 in the ESI. ${ }^{\dagger}$

The improved application range of this approach is evident from Fig. 6. While the product was not detectable applying the previous continuous flow conditions, a significant amount of the desired product can be analyzed after trapping the reaction mixture for 6.7 minutes.

As evident from Fig. 6, it is even possible to differentiate the enantiomers in the reaction solution since we equipped the device with a chiral stationary phase (Chiralpak IA-5, 5 $\mu \mathrm{m}$ diameter Chiral Technologies Europe, Daicel Corp., Osaka, Japan). A further improvement of the currently rather low chromatographic enantiomer resolution of 0.8 should be straightforward by using an adapted channel layout with an increased column length and smaller diameter phase material. In a set of semi-automated experiments (valve switching

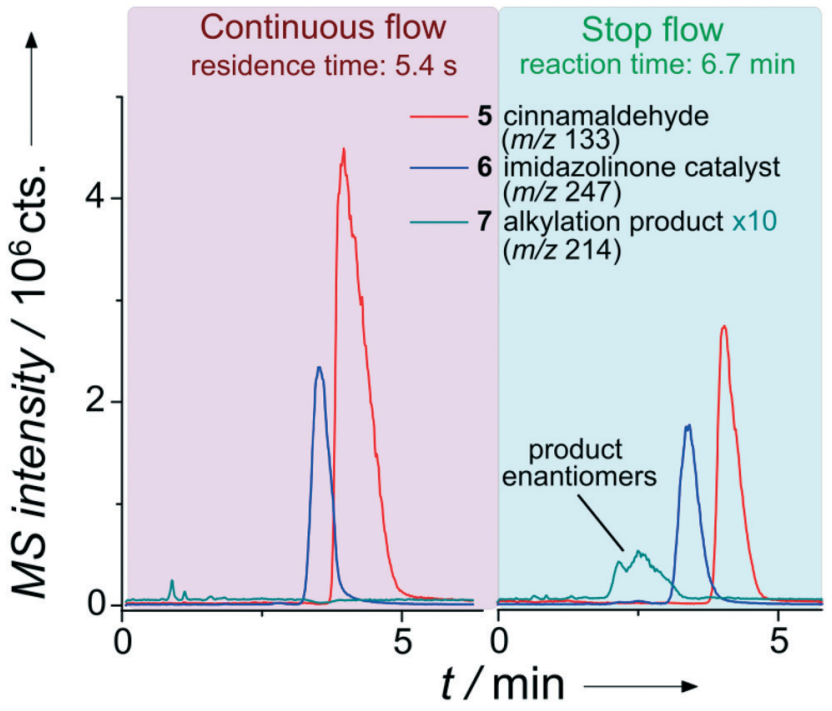

Fig. 6 Extracted ion chromatograms of the separation of an enantioselective iminium-catalyzed Friedel-Crafts alkylation (see Scheme $\mathrm{SI}-1 \dagger$ ) for two injections during a single run with chiral chipHPLC. Column: Chiralpak IA-5, particle diameter $5 \mu \mathrm{m}$, length $35 \mathrm{~mm}$. Mobile phase: $50 \mu \mathrm{min}^{-1}, \mathrm{MeOH} / \mathrm{H}_{2} \mathrm{O}(60 / 40$ vol\%) with $0.1 \%$ formic acid. Sample pumps: $10 \mu \mathrm{l} \mathrm{min}{ }^{-1}, \mathrm{MeOH} / \mathrm{H}_{2} \mathrm{O}$ (80/20 vol\%). Pinch: $10 \mu \mathrm{l}$ $\mathrm{min}^{-1}, \mathrm{MeOH} / \mathrm{H}_{2} \mathrm{O}(50 / 50$ vol\%). 8 bar elution pressure at the injection cross with immobilized sample plug at a linear flow rate of $0.88 \mathrm{~mm}$ $\mathrm{s}^{-1}$ over the column. Reactant inlet A: $4\left(0.25 \mathrm{~mol} \mathrm{l}^{-1}\right)$, reactant inlet $\mathrm{B}$ : $5\left(0.25 \mathrm{~mol} \mathrm{l}^{-1}\right), 10 \mathrm{~mol} \% 6$ (in relation to 5 ) each in $\mathrm{ACN} / \mathrm{H}_{2} \mathrm{O}(87 / 13$ vol\%).

pattern see Table SI-5 $\dagger$ ), we applied the stop-flow approach to kinetic investigations of the alkylation product formation, utilizing two different catalysts at $20 \mathrm{~mol} \%$ (with respect to 5) as well as a negative control. The results are shown in Fig. SI$16, \uparrow$ revealing the benefit of catalyst A (6), which is in good agreement with respective control batch experiments. No product formation was observed in the absence of a catalyst after 30 min reaction time. Although the sample concentrations in these reaction-monitoring experiments are typically rather high, we briefly evaluated the sensitivity of the system. Considering a signal-to-noise $(\mathrm{S} / \mathrm{N})$ ratio for the main fragment of cinnamaldehyd of about 3000 , the detection of even low nano-molar concentrations should be easily reached with this not-optimized set-up.

In conclusion, we have introduced a novel approach for the seamless integration of chemical reactions in micro-flow and micro-batch conditions, HPLC separation and electrospray ionization in one single microfluidic chip. With this approach chemical transformations at the microscale can be followed by LC-MS in quasi real time and great detail.

In future work, eluent compatibility limitations can be overcome by integrating trapping columns and multidimensional separation techniques. Such integrated reaction and analysis devices allow rapid studies of a great variety of chemical transformations like enantioselective catalysis. This novel tool is ideally suited for (automated) investigations of novel reactions, synthesis optimization and catalyst screening at high speed and minimal resource consumption. Thereby, 
the setup offers great potential as a "smart" automated system $^{61}$ using feedback from on-chip LC-MS to explore and optimize reactions at the microscale for high-throughput screening applications like in drug development or medical diagnostics.

\section{Experimental section}

Glass chips (borosilicate $\mathrm{BF}{ }^{\circledR 3} 3$ - dimensions: $45 \mathrm{~mm}$ length $\times 10 \mathrm{~mm}$ width $\times 2.2 \mathrm{~mm}$ height, semi-circular channels: 130 $\mu \mathrm{m}$ or $155 \mu \mathrm{m}$ in width and $45 \mu \mathrm{m}$ in depth) were produced by iX-factory (Dortmund, Germany, now part of micronit) by common photolithography, wet etching, powder-blasting and bonding methods according to our design specifications. The column head and outlet featured a slight narrowing to aid in the column generation process.

In the valve scheme presented in Fig. 4 for continuous flow operation without the possibility of trapping the reaction mixture, valve 'A' may be removed and ports 9 and 10 are then connected to the two reactor inlets at the microchip. The high-pressure syringe pumps were connected to the microfluidic circuitry with 1/16" PEEK tubing with $120 \mu \mathrm{m}$ ID, inline filters ( $2 \mu \mathrm{m}$ SST frit) and adapters to fit $360 \mu \mathrm{m}$ OD PEEK capillary tubing (all in grey box on the right). The remaining microfluidic setup consisted of $360 \mu \mathrm{m}$ OD PEEK capillary tubing of differing IDs and lengths: a) $75 \mu \mathrm{m}, 20$ cm; b) $50 \mu \mathrm{m} 15 \mathrm{~cm}$; c) $50 \mu \mathrm{m} 60 \mathrm{~cm}$; d) $50 \mu \mathrm{m} 30 \mathrm{~cm}$; e) 50 $\mu \mathrm{m} 13 \mathrm{~cm}$; f) $50 \mu \mathrm{m} 14.5 \mathrm{~cm}$. The injection loops each had a volume of $3.68 \mu \mathrm{l}$. Further detailed experimental information is given in the ESI. $\dagger$

This work was supported by the Studienstiftung des $d t$. Volkes (PhD scholarship J. J. Heiland), Chiral Technologies Europe (esp. Dr. Pilar Franco, providing support and chiral stationary phase material) and the Deutsche Forschungsgemeinschaft (DFG) for funding (FOR 2177).

\section{Notes and references}

1 C. Wiles and P. Watts, Green Chem., 2014, 16, 55.

2 F. G. Finelli, L. S. M. Miranda and R. O. M. A. de Souza, Chem. Commun., 2015, 51, 3708.

3 B. Gutmann, J.-P. Roduit, D. Roberge and C. O. Kappe, Angew. Chem., Int. Ed., 2010, 49, 7101.

4 A. Abou-Hassan, O. Sandre and V. Cabuil, Angew. Chem., Int. Ed., 2010, 49, 6268.

5 I. R. Baxendale, J. Chem. Technol. Biotechnol., 2013, 88, 519.

6 T. Noël and S. L. Buchwald, Chem. Soc. Rev., 2011, 40, 5010.

7 J. Wegner, S. Ceylan and A. Kirschning, Adv. Synth. Catal., 2012, 354, 17.

8 V. Hessel, D. Kralisch, N. Kockmann, T. Noël and Q. Wang, ChemSusChem, 2013, 6, 746.

9 R. L. Hartman, J. P. McMullen and K. F. Jensen, Angew. Chem., Int. Ed., 2011, 50, 7502.

10 J. E. Kreutz, A. Shukhaev, W. Du, S. Druskin, O. Daugulis and R. F. Ismagilov, J. Am. Chem. Soc., 2010, 132, 3128.
11 A. G. O'Brien, Z. Horváth, F. Lévesque, J. W. Lee, A. SeidelMorgenstern and P. H. Seeberger, Angew. Chem., Int. Ed., 2012, 51, 7028.

12 R. J. Ingham, C. Battilocchio, D. E. Fitzpatrick, E. Sliwinski, J. M. Hawkins and S. V. Ley, Angew. Chem., Int. Ed., 2015, 54, 144.

13 H. R. Sahoo, J. G. Kralj and K. F. Jensen, Angew. Chem., Int. Ed., 2007, 46, 5704.

14 F. Lévesque and P. H. Seeberger, Angew. Chem., Int. Ed., 2012, 51, 1706.

15 F. T. G. van den Brink, L. Büter, M. Odijk, W. Olthuis, U. Karst and A. van den Berg, Anal. Chem., 2015, 87, 1527.

16 K.-I. Min, T.-H. Lee, C. P. Park, Z.-Y. Wu, H. H. Girault, I. Ryu, T. Fukuyama, Y. Mukai and D.-P. Kim, Angew. Chem., Int. Ed., 2010, 49, 7063.

17 S. Kundu, A. S. Bhangale, W. E. Wallace, K. M. Flynn, C. M. Guttman, R. A. Gross and K. L. Beers, J. Am. Chem. Soc., 2011, 133, 6006.

18 K. Gilmore and P. H. Seeberger, Chem. Rec., 2014, 14, 410.

19 T. Rodrigues, P. Schneider and G. Schneider, Angew. Chem., Int. Ed., 2014, 53, 5750.

20 A. Nagaki, K. Imai, S. Ishiuchi and J.-i. Yoshida, Angew. Chem., Int. Ed., 2015, 54, 1914.

21 S. Stockinger, J. Gmeiner, K. Zawatzky, J. Troendlin and O. Trapp, Chem. Commun., 2014, 50, 14301.

22 A. J. deMello, Nature, 2006, 442, 394.

23 D. Belder, Angew. Chem., Int. Ed., 2009, 48, 3736.

24 M. L. Kovarik, D. M. Ornoff, A. T. Melvin, N. C. Dobes, Y. Wang, A. J. Dickinson, P. C. Gach, P. K. Shah and N. L. Allbritton, Anal. Chem., 2013, 85, 451.

25 Y. Wang, W.-Y. Lin, K. Liu, R. J. Lin, M. Selke, H. C. Kolb, N. Zhang, X.-Z. Zhao, M. E. Phelps, C. K. F. Shen, K. F. Faull and H.-R. Tseng, Lab Chip, 2009, 9, 2281.

26 S. J. Haswell, Nature, 2006, 441, 705.

27 S. Stockinger, J. Troendlin, F. Rominger and O. Trapp, Adv. Synth. Catal., 2015, 357, 3513.

28 K. S. Elvira, X. C. I. Solvas, R. C. R. Wootton and A. J. deMello, Nat. Chem., 2013, 5, 905.

29 V. Sans and L. Cronin, Chem. Soc. Rev., 2016, 45, 2032.

30 K. F. Jensen, B. J. Reizman and S. G. Newman, Lab Chip, 2014, 14, 3206.

31 M. Rasheed and T. Wirth, Angew. Chem., Int. Ed., 2011, 50, 357.

32 J. Yue, J. C. Schouten and T. A. Nijhuis, Ind. Eng. Chem. Res., 2012, 51, 14583.

33 X. Feng, B.-F. Liu, J. Li and X. Liu, Mass Spectrom. Rev., 2015, 34, 535.

34 X. Wang, L. Yi, N. Mukhitov, A. M. Schrell, R. Dhumpa and M. G. Roper, J. Chromatogr. A, 2015, 1382, 98.

35 K. M. Krone, R. Warias, C. Ritter, A. Li, C. G. Acevedo-Rocha, M. T. Reetz and D. Belder, J. Am. Chem. Soc., 2016, 138, 2102.

36 D. Belder, M. Ludwig, L. W. Wang and M. T. Reetz, Angew. Chem., Int. Ed., 2006, 45, 2463.

37 S. Ohla, R. Beyreiss, S. Fritzsche, P. Glaser, S. Nagl, K. Stockhausen, C. Schneider and D. Belder, Chem. - Eur. J., 2012, 18, 1240 . 
38 S. Fritzsche, S. Ohla, P. Glaser, D. S. Giera, M. Sickert, C. Schneider and D. Belder, Angew. Chem., Int. Ed., 2011, 50, 9467.

39 J. Hereijgers, T. Breugelmans and W. DeMalschea, J. Chem. Technol. Biotechnol., 2015, 90, 2122.

40 A. Odedra and P. H. Seeberger, Angew. Chem., Int. Ed., 2009, 48, 2699.

41 A. Buitrago Santanilla, E. L. Regalado, T. Pereira, M. Shevlin, K. Bateman, L.-C. Campeau, J. Schneeweis, S. Berritt, Z.-C. Shi, P. Nantermet, Y. Liu, R. Helmy, C. J. Welch, P. Vachal, I. W. Davies, T. Cernak and S. D. Dreher, Science, 2015, 347, 49.

42 J. P. McMullen, M. T. Stone, S. L. Buchwald and K. F. Jensen, Angew. Chem., Int. Ed., 2010, 49, 7076.

43 G. Desmet and S. Eeltink, Anal. Chem., 2013, 85, 543.

44 J. P. Kutter, J. Chromatogr. A, 2012, 1221, 72.

45 J. Xie, Y. Miao, J. Shih, Y.-C. Tai and T. D. Lee, Anal. Chem., 2005, 77, 6947.

46 P. A. Levkin, S. Eeltink, T. R. Stratton, R. Brennen, K. Robotti, H. Yin, K. Killeen, F. Svec and J. M. J. Fréchet, J. Chromatogr. A, 2008, 1200, 55.

47 J. Šesták, D. Moravcová and V. Kahle, J. Chromatogr. A, 2015, 1421, 2.

48 D. Geissler, J. J. Heiland, C. Lotter and D. Belder, Microchim. Acta, 2016, DOI: 10.1007/s00604-016-2012-3.
49 S. Thurmann, A. Dittmar and D. Belder, J. Chromatogr. A, 2014, 1340, 59.

50 S. Thurmann, L. Mauritz, C. Heck and D. Belder, J. Chromatogr. A, 2014, 1370, 33.

51 S. Thurmann, C. Lotter, J. J. Heiland, B. Chankvetadze and D. Belder, Anal. Chem., 2015, 87, 5568.

52 C. Lotter, J. J. Heiland, S. Thurmann, L. Mauritz and D. Belder, Anal. Chem., 2016, 88, 2856.

53 C. Lotter, E. Poehler, J. J. Heiland, L. Mauritz and D. Belder, Lab Chip, 2016, DOI: 10.1039/c6lc01138a.

54 D. E. Fitzpatrick, C. Battilocchio and S. V. Ley, ACS Cent. Sci., 2016, 2, 131.

55 C. Lotter, J. J. Heiland, V. Stein, M. Klimkait, M. Queisser and D. Belder, Anal. Chem., 2016, 88, 7481.

56 M. Fernandez-Suarez, S. Y. F. Wong and B. H. Warrington, Lab Chip, 2002, 2, 170.

57 L. F. Tietze, S. Brand, T. Brumby and J. Fennen, Angew. Chem., Int. Ed. Engl., 1990, 29, 665.

58 N. A. Paras and D. W. C. MacMillan, J. Am. Chem. Soc., 2001, 123, 4370.

59 J. F. Austin and D. W. C. MacMillan, J. Am. Chem. Soc., 2002, 124, 1172.

60 R. Khajuria, S. Dham and K. K. Kapoor, RSC Adv., 2016, 6, 37039.

61 B. J. Reizman and K. F. Jensen, Chem. Commun., 2015, 51, 13290. 